Check for updates

Cite this: RSC Adv., 2019, 9, 13325

Received 19th January 2019

Accepted 22nd April 2019

DOI: 10.1039/c9ra00470j

rsc.li/rsc-advances

\section{Biocatalytic oxidation of flavone analogues mediated by general biocatalysts: horseradish peroxidase and laccase $\uparrow$}

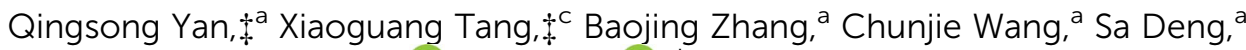 \\ Xiaochi Ma, ${ }^{a}$ Chao Wang, (D) ${ }^{a}$ Dawei Li, (D) ${ }^{* b}$ Shanshan Huang ${ }^{a}$ and Peipei Dong ${ }^{* a}$
}

\section{Introduction}

Oxidases are well known functional enzymes, which play an important role for the life of animals, plants and microorganisms. Due to their highly oxidative capability and advances in green chemistry, peroxidases have been widely applied to address many of the challenges of modern synthetic organic chemistry. ${ }^{1-7}$ Oxidases are known as a series of hemoproteins, possessing copper or ferric ions in their active sites to catalyze various oxidative transformations of organic and inorganic compounds using $\mathrm{H}_{2} \mathrm{O}_{2}$ and other related oxides as oxidizing agents. In general, stable radicals formed in the presence of oxidases could undergo several coupling or reoxidation reactions, which further afforded the polyphenols.

One of the most common peroxidases is horseradish peroxidase (HRP, EC 1.11.1.7) with a molecular weight of 40 $\mathrm{kDa}$, which contains at least 30 kinds of HRP isoenzyme forms. The HRP isoenzyme C (HRP-C) is the most abundant one, which

${ }^{a}$ College of Pharmacy, Research Institute of Integrated Traditional and Western Medicine, Dalian Medical University, Dalian 116044, P. R. China. E-mail: dongpeipei11@163.com

${ }^{b}$ The First Affiliated Hospital of Dalian Medical University, No. 222 Zhongshan Road, Dalian 116011, P. R. China. E-mail: lidw87@163.com

'Medicial College of Chifeng University, Chifeng 02400, P. R. China

$\dagger$ Electronic supplementary information (ESI) available. See DOI: $10.1039 / \mathrm{c} 9 \mathrm{ra} 00470 \mathrm{j}$

‡ Q. S. Yan and X. G. Tang contributed equally to this work. consists of 308 amino acid residues, 4 disulphide bridges between cysteine residues as well as a heme group [iron(III) protoporphyrin IX] and two calcium atoms. ${ }^{3,8}$ It is able to utilize hydrogen peroxide to catalyze the one-electron oxidation for a wide range of aromatic substrates with the formation of various polymers (Fig. 1).

Distinguished from HRP, laccase (Lac. EC 1.10.3.2), known as multi-copper oxidase, is widely distributed in natural sources, such as fungi, bacteria, plant, insects and lichens, with the

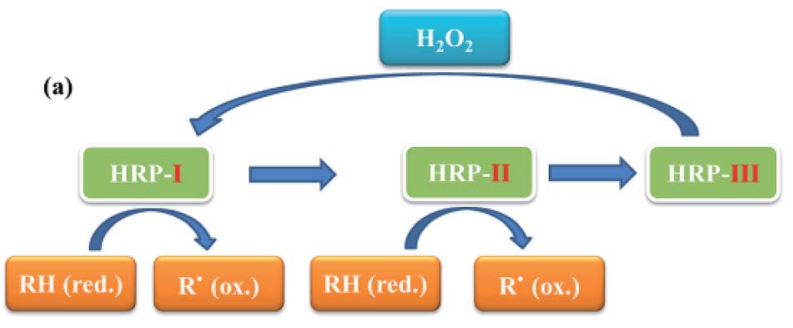

(b)

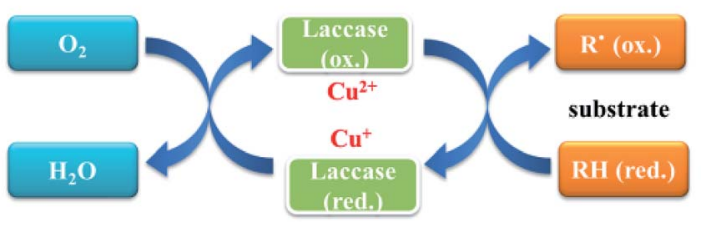

Fig. 1 Proposed catalytic pathways of horseradish peroxidase (HRP), (a) and laccase (b). HRP: horseradish peroxidase; RH: substrate; R: free radical of substrate. 
molecular mass range of 50-130 kDa.,10 Laccases have a functional unit that consists of four coppers, which could catalyze the oxidation of various organic compounds, such as diphenols, polyphenols, diamines, aromatic amines, benzeneethiols, and substituted phenols (Fig. 1). ${ }^{1}$

Flavones known as plant phenols are widely distributed in natural resources, which displayed multiple biological effects. In addition, polyphenols with high molecular weight showed better bioactivities, such as the rutin polymer and polycatechin with excellent superoxide scavenging activity. ${ }^{\mathbf{1 1}}$ In the previous studies, some flavones have been transformed by laccase or HRP to afford the oxidation derivatives, which have drawn more and more attention of researchers for the application in biosynthesis. ${ }^{\mathbf{1 2}-16}$ However, the enzymatic oxidations of flavones catalyzed by oxidases had been reported rarely with limited hypothetical mechanism.

The present study comprehensively compared the oxidation reactions of different flavone analogues mediated by HRP or laccase, respectively. The oxidative products have been prepared and identified by various spectral methods. Furthermore, the enzymatic oxidation characteristics have been studied on the basis of the flavone structure diversities and oxidase species. The oxidation mechanisms of various flavones mediated by HRP or laccase have been discussed on the basis of radical reaction, molecular docking and kinetics analyses.

\section{Results and discussion}

\section{Oxidation of flavone analogues mediated by oxidases}

Flavones also known as 2-benzyl chromone, are obtained from plants as the bioactive substances. ${ }^{\mathbf{1 6}}$ According to the difference of sub-structure, the flavone family mainly included flavones, flavonols, flavanones, isoflavones and chalcones, respectively (Fig. 2). Due to the phenolic groups, flavones are classified to be plant phenols. In the present study, various flavone analogues were used as the substrates to evaluate the oxidation capabilities of two oxidases HRP and laccase. The screening experiment was performed in primary reaction system with the

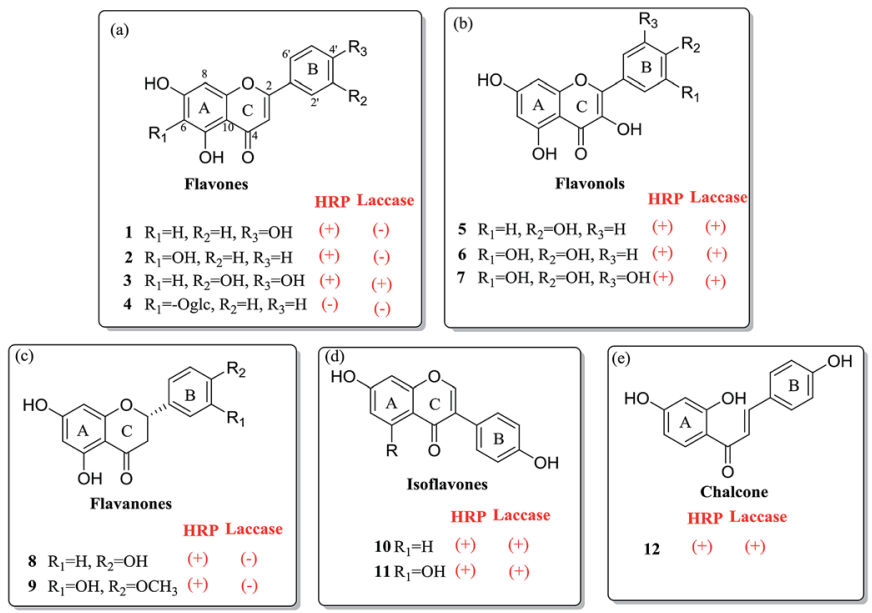

Fig. 2 The screening oxidation of flavone analogues mediated by peroxidases: HRP and laccase. (a) Flavones; (b) flavonols; (c) flavanones; (d) isoflavones; (e) chalcones. products detected by HPLC-DAD. On the basis of the detected products of various flavone analogues, the capabilities of HRP and laccase to catalyze the oxidation reaction have been analyzed in detail. HRP could mediate the oxidation of most flavone analogues possessing one or more phenolic groups, except for the flavone glycoside (4) (Fig. 2). The saccharide group enlarges the molecular mass of the substrate, which leading to the steric effect between flavone substrate and HRP. For the laccase, more interesting features were observed according to the structure distinction. When flavone (3) possesses two adjacent phenolic groups, the oxidation of these substrates could be catalyzed by laccase. Flavonols $(\mathbf{5}, \mathbf{6}, \mathbf{7})$, isoflavones $(\mathbf{1 0}, \mathbf{1 1})$ and chalcone $(\mathbf{1 2})$ with one or more phenolic groups were the effective substrates of laccase. On the other hand, flavanones $(\mathbf{8}, \mathbf{9})$ could not be oxidated by laccase. On the basis of the screening experiment, HRP displayed the stronger capability to mediate the enzymatic oxidation of flavone analogues, than that of laccase.

\section{Preparation and identification of the oxidated products}

In order to investigate the enzymatic mechanism, the present study attempted to prepare the oxidated products of various flavone analogues mediated by HRP or laccase. When these flavonoid substrates with multiple or unstable products were got rid, the oxidation of these flavone analogues 1, 5, 8, 10 and 12 transformed by HRP or laccase yielded the oxidated products or polyflavones. On the basis of spectroscopic data (ESI-MS, HRESI-MS, $\left.{ }^{1} \mathrm{H}-\mathrm{NMR},{ }^{13} \mathrm{C}-\mathrm{NMR}, 2 \mathrm{D}-\mathrm{NMR}\right)$ and literatures, ${ }^{17-21}$ the products were determined as dimers 1a (yield 37\%), 8a (yield 18\%), 8 b (yield 45\%), 10a (yield 17\%), $10 b$ (yield 8\%), 10c (yield $12 \%$ ), 12a (yield 19\%), 12b (yield 21\%) mediated by HRP and oxidated flavonol 5a (yield 31\%) mediated by laccase (Scheme 1). The ${ }^{1} \mathrm{H}$ and ${ }^{13} \mathrm{C}$ NMR data were assigned in Tables $\mathrm{S} 1$ and $\mathrm{S} 2$ (ESI) $\dagger$ respectively. In the screening experiment, substrates $\mathbf{1 , 8}$, 10 and 12 could be catalyzed by HRP to afford the dimers, and 10, 12 gave the same products in the laccase enzymatic systems. For flavonol 5, multiple products were observed with HRP as the mediated enzyme, and the major product 5 a was obtained using laccase as the catalyst. The structures of diflavones suggested that the polymerization positions located at the rings $\mathrm{B}$ and $\mathrm{C}$ generally. The oxidation of kaempferol (5) also occurred at the ring $\mathrm{C}$ of chromone. The oxidation of phenolic substrates catalyzed by oxidase (HRP or laccase) was known as phenolic radical reaction through electronic transfer. According to the chemical structures of various substrates $(\mathbf{1}, \mathbf{5}, \mathbf{8}, \mathbf{1 0}$, and 12) and the corresponding products, the radical reaction courses were hypothesized as shown in Scheme 1.

As shown in Scheme 1, the proposed radical reactions were initiated at the phenolic groups of ring $\mathrm{B}$ in the flavone structures, which indicated that the $\mathrm{O}-\mathrm{H}$ bond in ring $\mathrm{B}$ was inclined to be dissociated in the presence of HRP or laccase. ${ }^{22}$ The bond energies of different phenolic groups of various flavones were calculated as shown in Table 1 . The phenolic groups at C-5 position of flavones 1, 5 and $\mathbf{8}$ were not calculated for the intramolecular hydrogen bond between 5-OH and 4-ketone. Thus, it was obvious that the $4^{\prime}-\mathrm{OH}$ in various flavones had smaller bond 

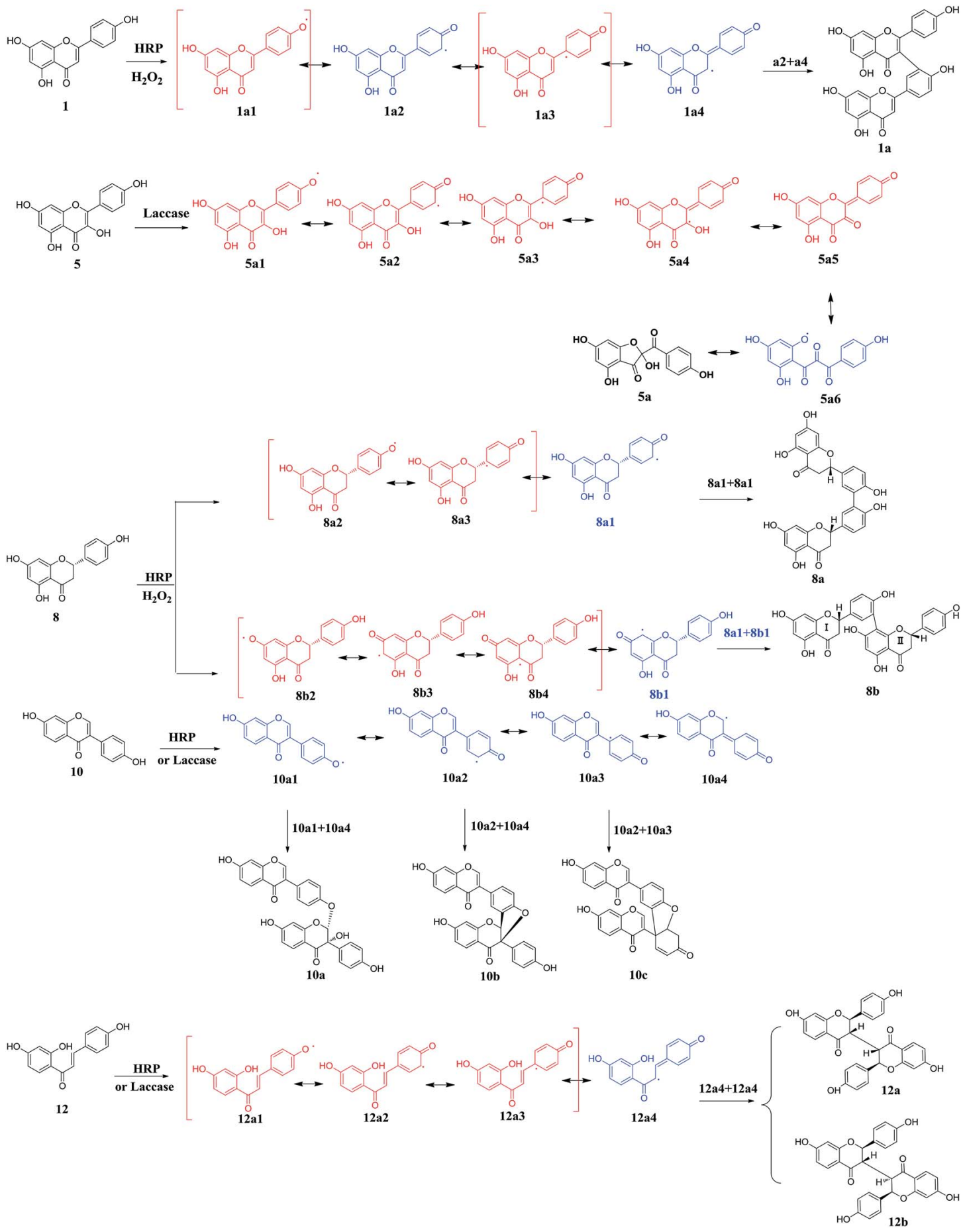

Scheme 1 The predicted radical reactions of flavones mediated by HRP or laccase.

energies than 7-OH, which indicated that the $\mathrm{O}-\mathrm{H}\left(\mathrm{C}-4^{\prime}\right)$ bonds were inclined to be dissociated catalyzed by HRP or laccase. So, the radical reactions of flavones were predicted as shown in Scheme 1 , and $4^{\prime}-\mathrm{OH}$ was the trigger of radical reaction.

\section{Comparison of the flavones transformation mediated by HRP and laccase}

As the peroxidases, HRP and laccase could catalyze the various oxidation of phenolic substrates. However, the different capabilities of HRP and laccase were related to their oxidationreduction potential $(\mathrm{rH})$. When the substrates displayed the lower oxidation-reduction potential $(\mathrm{rH})$ than HPR $(<-0.2070$ $\mathrm{V}$ ) or laccase $(0.5-0.8 \mathrm{~V})$, the oxidation could be catalyzed by peroxidases. On the basis of the structures of various substrates and their corresponding phenolic radicals, the oxidationreduction potentials $(\mathrm{rH})$ of these flavone analogues were calculated as $\mathbf{1}(\Delta E=-0.027 \mathrm{~V}), 5(\Delta E=-0.026 \mathrm{~V}), 8(\Delta E=$ $-0.027 \mathrm{~V}), 10(\Delta E=-0.027 \mathrm{~V}), 12(\Delta E=-0.026 \mathrm{~V})$ using Nernst 
Table 1 The bond energy of different phenolic groups of flavones

\begin{tabular}{|c|c|c|c|c|c|}
\hline Flavones & $\begin{array}{l}\text { Phenolic } \\
\text { group }\end{array}$ & $\begin{array}{l}\mathrm{H}-\mathrm{O} \text { energy } \\
\left(\mathrm{kcal} \mathrm{mol}^{-1}\right)\end{array}$ & Flavones & $\begin{array}{l}\text { Phenolic } \\
\text { group }\end{array}$ & $\begin{array}{l}\mathrm{H}-\mathrm{O} \text { energy } \\
\left(\mathrm{kcal} \mathrm{mol}^{-1}\right)\end{array}$ \\
\hline \multirow[t]{2}{*}{1} & $4^{\prime}-\mathrm{OH}$ & 67.6 & 10 & $4^{\prime}-\mathrm{OH}$ & 68.6 \\
\hline & 7-OH & 72.5 & & 7-OH & 72.6 \\
\hline \multirow[t]{2}{*}{5} & $4^{\prime}-\mathrm{OH}$ & 68.3 & 12 & $4^{\prime}-\mathrm{OH}$ & 66.8 \\
\hline & 7-OH & 72.2 & & 7-OH & 69.7 \\
\hline \multirow[t]{2}{*}{8} & $4^{\prime}-\mathrm{OH}$ & 75.6 & & & \\
\hline & 7-OH & 70.3 & & & \\
\hline
\end{tabular}

equation. All of the flavones displayed similar and lower oxidation-reduction potentials than this of HRP, which confirmed the oxidation of these flavones mediated by HRP.

It was known that the crystal structures of HRP and laccase were unambiguous, with the active centers HEME and copper ions respectively. The present work has performed the molecular docking to analysis the reaction mechanism between flavone analogues and HPR and laccase. Molecular docking revealed that flavone analogues $1,5,8,10$, and 12 could dock into the HEME active pocket of HRP well with the high probabilities as 98\%, 93\%, 90\%, 100\% and 90\%, respectively.

As shown in Fig. 3, all of the flavone analogues bound to HPR with the optimal conformations, which displayed the ring B of these flavones docked into the HEME active pocket of HRP. So, the $4^{\prime}-\mathrm{OH}$ groups of these flavones were the nearest phenolic groups to the $\mathrm{Fe}$ atoms of HEME, further indicating the preferred formation of $\mathrm{C}-4^{\prime}$ phenolic radicals for the enzymatic oxidation of flavones. The binding energies calculation also suggested that all of the flavones bound to horseradish peroxidase with comparable binding affinity. Thus, HRP displayed a strong capability to catalyze the oxidation of flavones with the favorable $\mathrm{C}-4^{\prime}$ phenolic radicals.

For the laccase, molecular docking revealed that most of the flavones bound to the surface of laccase (Fig. 4). And, few molecular could dock into to the active pocket of laccase possessing $\mathrm{Cu}$ ions. Among these flavones, more molecula of kaemferol (5) and isoliquiritigenin (12) bound to the sites close to the $\mathrm{Cu}$ ions active center of laccase, which suggested the

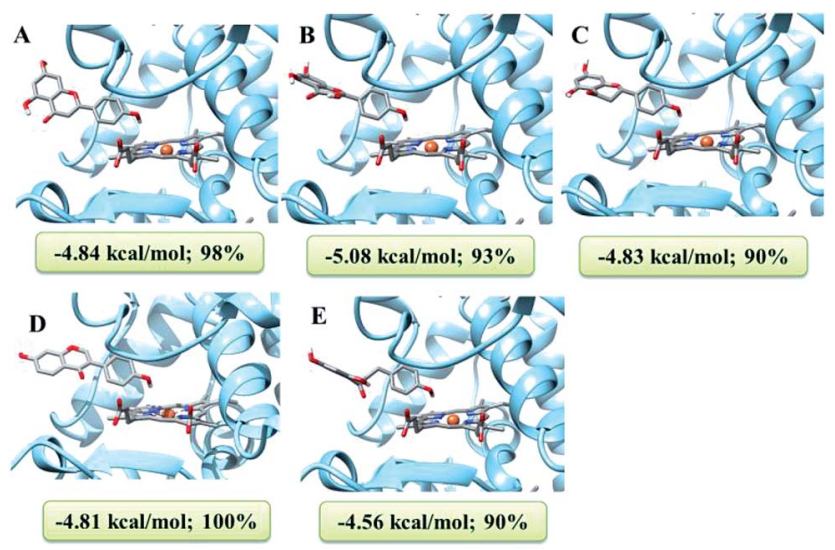

Fig. 3 Docking analysis of flavones and HRP together with the binding energy and docking probability. (A) 1; (B) 5; (C) 8; (D) 10; (E) 12; brown ball is Fe atom and green ball is Ca ion of HEME. preferred substrates 5 and $\mathbf{1 2}$ of laccase. Therefore, the molecular docking results also could confirm the low reaction efficiency of flavones catalyzed by laccase.

\section{Kinetics analysis of the oxidation of flavones catalyzed by HRP and laccase}

In the present work, kinetics analyses have been carried out to investigate the oxidation characteristics of HRP and laccase towards the various flavone analogues. For HRP, the kinetics behaviors of $1,8,10$ and 12 to form corresponding products mediated by HRP were studied as shown in Fig. 5. Flavone apigenin (1), and isoflavone daidzein (10) with different products followed the Hill kinetic model (Fig. 5A, D-F), as well as the kinetic parameters were also analyzed systematically (Table 2). Especially, at the low concentration of 1, the obvious substrate active process was observed for Hill kinetic model $(n=2.944)$. The $K_{\mathrm{m}}$ values also indicated that apigenin $\left(K_{\mathrm{m}} 163.5 \mu \mathrm{M}\right)$ had the better affinity towards HRP than daidzein. On the other hand, flavanone naringenin (8) and chalcone isoliquiritigenin (12) displayed substrate inhibition kinetics characteristics within the range of substrate concentrations tested in the kinetic exhibited a stronger substrate inhibitory effect for the oxidation catalyzed by HRP. The kinetic behaviors of the oxidation of the substrate 5, 10 and $\mathbf{1 2}$ transformed by laccase were also investigated as shown in Fig. 6. Flavonol 5 followed substrate inhibition kinetic model as well as $\mathbf{1 0}$ and $\mathbf{1 2}$ followed the Hill-kinetic model. The kinetic parameters exhibited that flavonol 5 had small affinity towards laccase $\left(K_{\mathrm{m}} 8288 \pm 401\right.$ $\mu \mathrm{M})$ and weak inhibitory effect on laccase $\left(K_{\mathrm{i}} 1656 \mu \mathrm{M}\right)$ (Table 3$)$. The kinetic parameters analysis displayed big $K_{\mathrm{m}}$ and small $V_{\max }$ for these substrates, which suggested the inefficient oxidation of these flavone analogues mediated by laccase compared with the oxidation of flavone analogues mediated by HRP.

\section{Experimental}

\section{Apparatus}

${ }^{1} \mathrm{H}$ NMR and ${ }^{13} \mathrm{C}$ NMR spectra were acquired on Bruker 501 spectrometer. ESIMS and LC-MS ${ }^{n}$ were performed on an API 3200 Triple Quadrupole Mass spectrometer (MS/MS) equipped with an electrospray ionization (ESI) source (AB, Sciex). HPLC analysis were carried out on an Ultimate 3000 system with quaternary delivery system, degasser, autosampler, UV-detector, and YMC ODS $(4.6 \times 150 \mathrm{~mm}, 5 \mu \mathrm{m})$ analytical column. Preparative HPLC experiments were performed using an Agel instrument with a UV detector and a YMC-Pack ODS-A column $(250 \times 20 \mathrm{~mm}, 5 \mu \mathrm{m})$. Constant temperature oscillator (ZHWY2102C) was produced by Shanghai Zhicheng Analysis Instrument Manufacturing Co., Ltd (China). The constant temperature mixing apparatus (MSC-100) was purchased from Hangzhou Allsheng Instruments Co., Ltd (China).

\section{Materials}

All chemical solvents, including dichloromethane, ethyl acetate, petroleum ether $\left(60-90^{\circ} \mathrm{C}\right)$, acetone, methanol, and chemical 

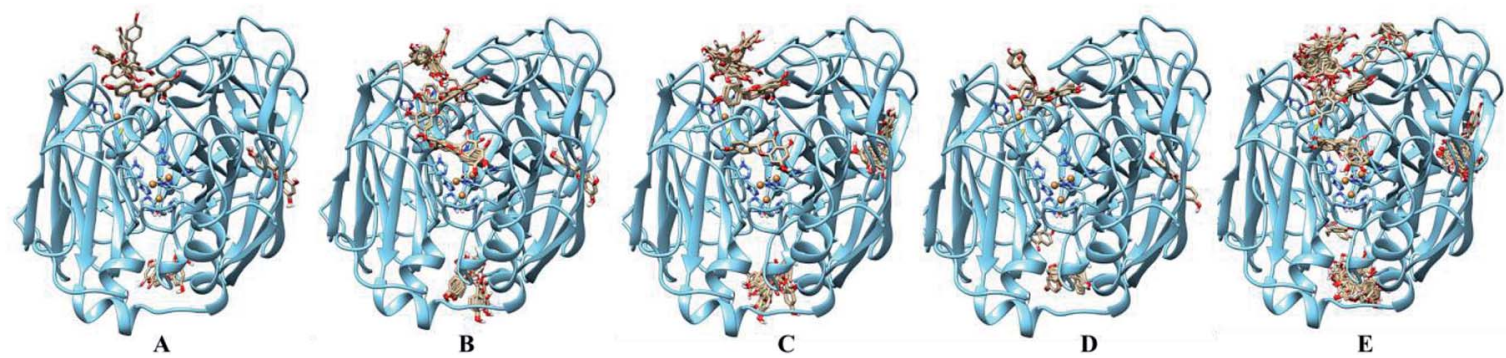

Fig. 4 Docking analysis of flavones and laccase. (A) 1; (B) 5; (C) 8; (D) 10; (E) 12; brown balls are Cu ions.
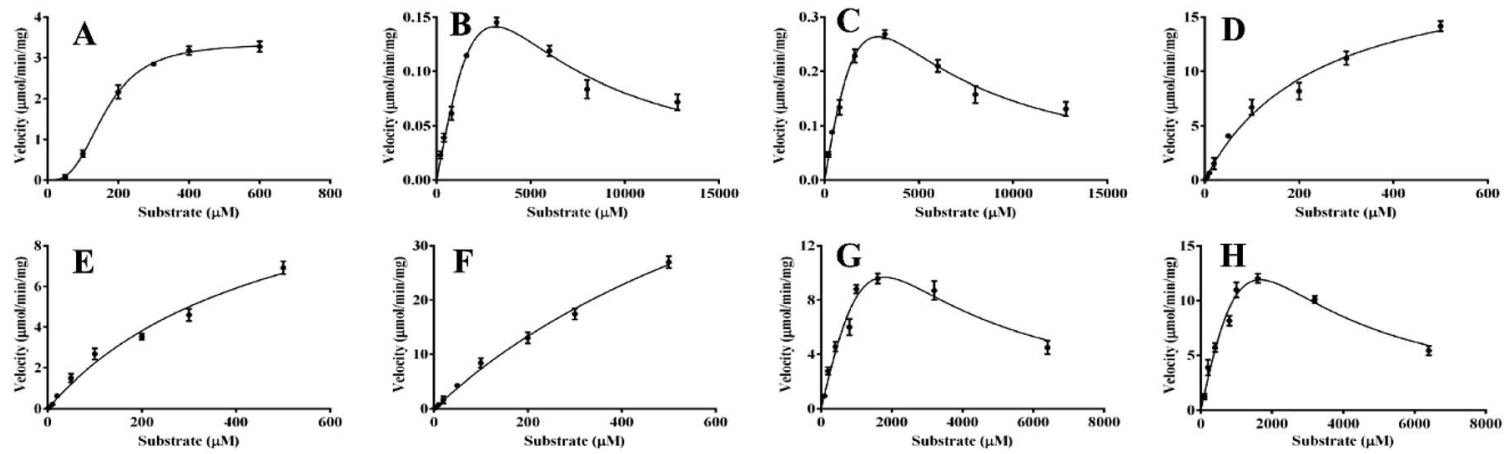

Fig. 5 The enzymatic kinetics of the oxidation of flavones mediated by HRP. (A) 1a; (B) 8a, (C) 8b; (D) 10a; (E) 10b; (F) 10c; (G) 12a; (H) 12b.

reagents, such as hydrogen peroxide $\left(\mathrm{H}_{2} \mathrm{O}_{2}\right)$, citric acid, disodium hydrogen phosphate $\left(\mathrm{Na}_{2} \mathrm{HPO}_{4}\right)$, and dimethyl sulfoxide (DMSO), were A.R. grade and obtained from Sinopharm Chemical Reagent Beijing Co., Ltd. Dimethyl sulfoxide- $d_{6}$ (DMSO- $d_{6}$ ) was produced by Cambridge Isotope Laboratories, Inc. Methanol and acetonitrile for HPLC analysis were of chromatographic grade (SIGMA, USA). Horseradish peroxidase (HRP, >250 $\mathrm{U} \mathrm{mg}^{-1}$ ) was purchased from J\&K Scientific Ltd. Laccase from Trametes versicolor $\left(120 \mathrm{U} \mathrm{g}^{-1}\right)$ was obtained from Yuanye Biological Scientific Ltd (Shanghai, China).

\section{Biotransformation of flavones by HRP}

Screen scale biotransformation was conducted in a $1 \mathrm{~mL}$ reaction system. $0.25 \mathrm{mg}$ of HRP was dissolved in $94 \mu \mathrm{L}$ of buffer (citric acid-hydrogen phosphate buffer solution, $\mathrm{pH}$ 3.0). One milligram of substrate (flavonoid) was dissolved in $376 \mu \mathrm{L}$ of water, $376 \mu \mathrm{L}$ of acetone, and $150 \mu \mathrm{L}$ of buffer. The HRP solution and substrate solution was mixed up, which was incubated at

Table 2 Kinetic parameters of flavones determined by HRP

\begin{tabular}{|c|c|c|c|c|}
\hline Products & $\begin{array}{l}V_{\max }\left(\mu \mathrm{mol} \min ^{-1}\right. \\
\left.\mathrm{mg}^{-1}\right)\end{array}$ & $K_{\mathrm{m}}(\mu \mathrm{M})$ & $n$ & $K_{\mathrm{i}}(\mu \mathrm{M})$ \\
\hline $1 \mathrm{a}$ & $3.358 \pm 0.6$ & $163.5 \pm 3.7$ & 2.944 & \\
\hline $8 \mathbf{8}$ & $1.790 \pm 0.2$ & $19131 \pm 164$ & & 533.0 \\
\hline $8 \mathbf{b}$ & $2.489 \pm 0.8$ & $11988 \pm 143$ & & 673.7 \\
\hline 10a & $25.64 \pm 1.3$ & $404.6 \pm 5.8$ & 0.8561 & \\
\hline 10b & $15.08 \pm 1.2$ & $775.0 \pm 21$ & 0.8266 & \\
\hline $10 \mathrm{c}$ & $56.45 \pm 2.5$ & $694.2 \pm 36$ & 0.9460 & \\
\hline $12 \mathrm{a}$ & $143.5 \pm 4.1$ & $12477 \pm 1790$ & & 262.7 \\
\hline $12 b$ & $165.0 \pm 4.7$ & $11196 \pm 45$ & & 266.1 \\
\hline
\end{tabular}

$400 \mathrm{rpm}$ at $25{ }^{\circ} \mathrm{C}$. Five minutes later, $4 \mu \mathrm{L}$ of a $10 \% \mathrm{H}_{2} \mathrm{O}_{2}$ aqueous solution was added to the above mixture. The reaction was terminated by the addition of $1 \mathrm{~mL}$ ice-acetonitrile after 30 minutes followed by centrifugation at $20000 \times g$ for $20 \mathrm{~min}$. The supernatant was analyzed by HPLC-DAD.

\section{Biotransformation of flavones by laccase}

The incubation system for the laccase biotransformation contained $0.5 \mathrm{mg}$ laccase (dissolved in $650 \mu \mathrm{L}$ citric acid-hydrogen phosphate buffer solution, $\mathrm{pH} 4.0$ ) and $0.5 \mathrm{mg}$ flavonoid (dissolved in $350 \mu \mathrm{L}$ acetone) in a final volume of $1 \mathrm{~mL}$. After $6 \mathrm{~h}$ incubation at $30{ }^{\circ} \mathrm{C}$, the reaction was terminated by the addition of $1 \mathrm{~mL}$ iceacetonitrile, followed by centrifugation at $20000 \times g$ for $20 \mathrm{~min}$. The supernatant was subjected to HPLC-DAD for analysis.

\section{Preparation of oxidated flavones}

The preparative biotransformation was conducted under the above-mentioned conditions, but $200 \mathrm{mg}$ of the substrates were used. The reaction solution was extracted with $\mathrm{CH}_{2} \mathrm{Cl}_{2}$ and purified by using the pre-HPLC instrument with a C18 ODS

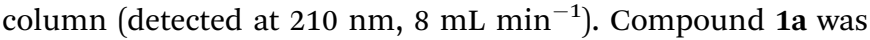
obtained at retention time $20.4 \mathrm{~min}$ with $\mathrm{CH}_{3} \mathrm{CN}$-water (45\% : 55\%, 0.3\% trifluoroacetic acid v/v). Compound 5a were isolated at retention time 28.8 min eluted by $\mathrm{CH}_{3} \mathrm{CN}$-water (20\% : 80\%, 0.3\% trifluoroacetic acid v/v). Compounds 8a and 8b were purified by $\mathrm{CH}_{3} \mathrm{CN}$-water (45\% : 55\%, 0.3\% trifluoroacetic acid $\mathrm{v} / \mathrm{v}$ ) at retention time $36.6 \mathrm{~min}$ and $67.2 \mathrm{~min}$, respectively. Compounds 10a, 10b and 10c were isolated with $\mathrm{CH}_{3} \mathrm{CN}$-water (35\%:65\%, $0.3 \%$ trifluoroacetic acid $\mathrm{v} / \mathrm{v}$ ) at retention time $30.5 \mathrm{~min}, 42 \mathrm{~min}$ and $54 \mathrm{~min}$, respectively. 

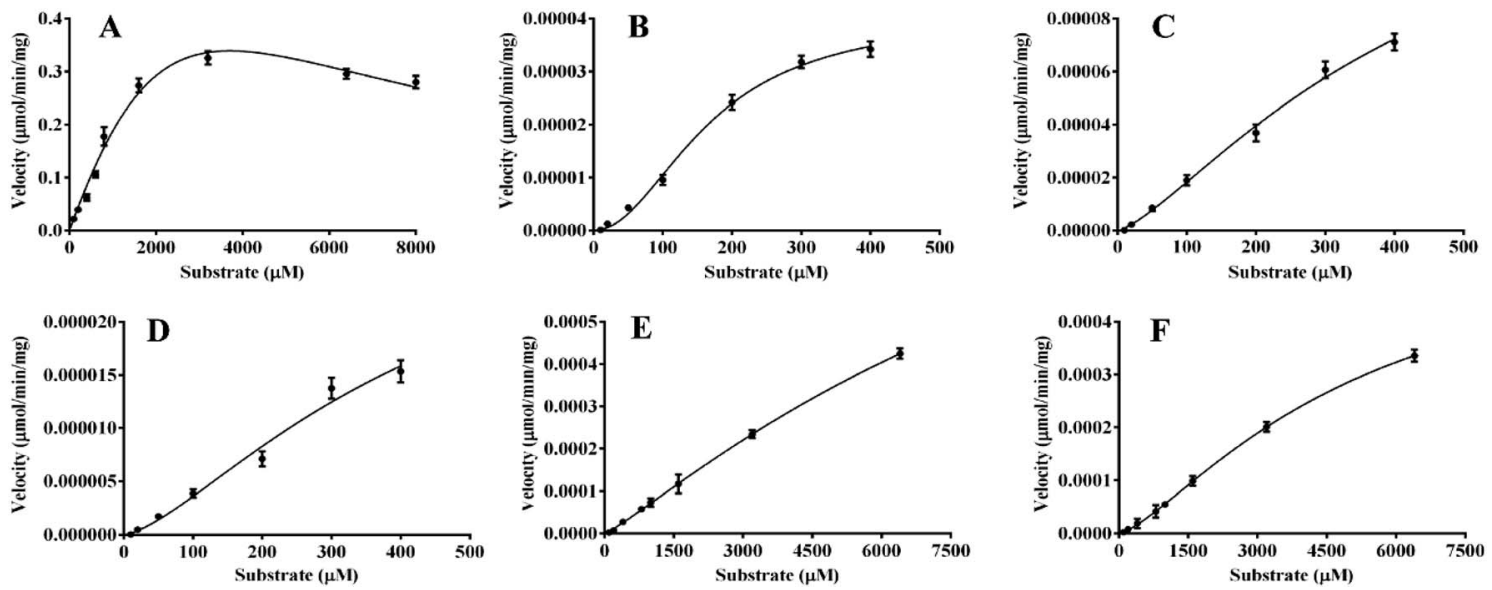

Fig. 6 The enzymatic kinetics behaviors of the oxidation of flavones mediated by laccase. (A) 5a; (B) 10a; (C) 10b; (D) 10C; (E) 12a; (F) 12b.

Table 3 Kinetic parameters of flavones determined by laccase

\begin{tabular}{|c|c|c|c|c|}
\hline Products & $\begin{array}{l}V_{\max }\left(\mu \mathrm{mol} \mathrm{min} \operatorname{mon}^{-1}\right. \\
\left.\mathrm{mg}^{-1}\right)\end{array}$ & $K_{\mathrm{m}}(\mu \mathrm{M})$ & $n$ & $K_{\mathrm{i}}$ \\
\hline $5 \mathbf{a}$ & $1.856 \pm 0.3$ & $8288 \pm 401$ & & 1656 \\
\hline 10a & $4.069 \pm 0.4 \times 10^{-5}$ & $167.6 \pm 10.6$ & 2.035 & \\
\hline $10 \mathrm{~b}$ & $3.333 \pm 0.3 \times 10^{-5}$ & $427.9 \pm 23$ & 1.452 & \\
\hline $10 \mathrm{c}$ & $1.523 \pm 0.6 \times 10^{-4}$ & $430.9 \pm 32$ & 1.363 & \\
\hline $12 a$ & $1.084 \pm 0.2 \times 10^{-3}$ & $9166 \pm 615$ & 1.224 & \\
\hline $12 b$ & $5.601 \pm 0.7 \times 10^{-4}$ & $4810 \pm 373$ & 1.418 & \\
\hline
\end{tabular}

Compounds 12a and 12b were obtained at retention time $36.5 \mathrm{~min}$ and $53 \mathrm{~min}$, respectively eluted by $\mathrm{CH}_{3} \mathrm{CN}$-water (33\% : 67\%, 0.3\% trifluoroacetic acid v/v).

\section{Quantitative analysis of biotransformation for kinetics investigation}

An Agilent 1200 HPLC system possessed quaternary delivery system, degasser, autosampler, UV-detector, and Elite SinoChorm ODS-BP $(2.1 \times 150 \mathrm{~mm}, 5 \mu \mathrm{m})$ analytical column was used for separation. The mobile phase consisted of acetonitrile$0.1 \%$ formic acid aqueous solution at a flow rate of 450 $\mu \mathrm{L} \min ^{-1}$. An Applied Biosystems MDS Sciex API 3200 Triple Quadrupole Mass Spectrometer (MS/MS) equipped with electrospray ionization (ESI) source was applied for the target products analysis. The system was operated in negative mode with the following values: compounds $1 \mathrm{a}$ (ions $538.8 \rightarrow 387.2$ ); 8a (540.8 $\rightarrow$ 415.0); 8b (540.8 $\rightarrow$ 389.0); 10a (523.0 $\rightarrow$ 269.0); 10b $(504.8 \rightarrow 369.0) ; 10 c(504.9 \rightarrow 252.0) ; 12 a(509.1 \rightarrow 403.1)$; $12 \mathrm{~b}(509.0 \rightarrow 403.0)$. The optimized ion spray voltage and temperature were set at $4500 \mathrm{~V}$ and $500{ }^{\circ} \mathrm{C}$, respectively. The curtain gas (CUR) flow was $20 \mathrm{~L} \mathrm{~min}^{-1}$; gas 1 and gas 2 (nitrogen) were set at 30 and $40 \mathrm{~L} \mathrm{~min}^{-1}$, respectively, and dwell time was $150 \mathrm{~ms}$. Nitrogen was used as both curtain and collision gas, controlled at 13 and 6 psi, respectively. Quantification assay was performed using multiple reaction monitoring.

\section{Molecular docking}

The protein structures of horseradish peroxidase (PDB ID: $1 \mathrm{H} 5 \mathrm{~A})^{23}$ and laccase (PDB ID: $\left.1 \mathrm{KYA}\right)^{24}$ were represented by CHARMM 22 force field parameters ${ }^{25}$ in order to properly model the HEME motif of horseradish peroxidase, Cu coordination of laccase, and disulfide bonds within each protein. The initial ligand structure was taken from the result of DFT calculations, and prepared using the PRODRG server (http:// davapc1.bioch.dundee.ac.uk/cgi-bin/prodrg). ${ }^{26}$

AutoDock 4.2 programs ${ }^{27}$ were used to perform all dockings. Autogrid program was used to pre-calculate grid maps of interaction energies for various atom types. The grid box was set sufficiently large to encompass the entire protein surface. Blind docking was performed using the Lamarckian generic algorithm as the searching method, and the default parameters for other docking settings were applied. A total of 100 conformations of each ligand were searched relative to each protein structure. The occurrence frequency of the ligand in different binding sites of the protein was calculated as indicative of the occupation propensity. The lowest binding energy in terms of docking scoring functions was also shown.

\section{Conclusions}

Horseradish peroxidase and laccase as the important biosynthesis enzymes, could catalyze the various oxidation of phenolic compounds. As the vital phenolic substances, flavone analogues with abundant natural resources and significant bioactivities, could be modified to form the series of potential bioactive molecules. Therefore, oxidases were applied to effectively catalyze the oxidation of various flavone analogues in this work. After the screening experiments, HRP had the preferred capability to oxidize most of the phenolic flavones, but only flavonols, isoflavones and chalcones with phenolic groups and dihydroxylflavones could become the effective substrates of laccase to yield the similar products with that mediated by HRP. For these phenolic groups at different positions of flavones, the $\mathrm{O}-\mathrm{H}$ bond energy analysis revealed the lowest bound energy of 
$4^{\prime}-\mathrm{OH}$ in the B-ring of flavones, which implying that the $4^{\prime}$ radical was the trigger of these radical reactions. Furthermore, 4 -OH were nearest groups to the HEME active pocket of HRP by in silico molecular docking. However, for laccase, due to most flavones docking into its surface, the laccase did not efficiently catalyze the oxidation of flavones. Kinetic behaviors of the oxidation for these flavone analogues mediated by peroxidases exhibited the Hill and substrate inhibition kinetic models. In summary, our present work systemically characterized the oxidation of flavone analogues mediated by HRP and laccase, and some novel dimers were successfully prepared and identified.

\section{Conflicts of interest}

The authors declare no competing financial interest.

\section{Acknowledgements}

This research program was supported financially by the National Natural Science Foundation of China (No. 81803683 and 81872970) and Dalian Youth Science and Technology Star Project (2017RQ046).

\section{Notes and references}

1 S. Witayakrana and A. J. Ragauskas, Adv. Synth. Catal., 2009, 351, 1187-1209.

2 M. Mogharabia and M. A. Faramarzia, Adv. Synth. Catal., 2014, 356, 897-927.

3 G. R. Lopes, D. C. G. A. Pinto and A. M. S. Silva, RSC Adv., 2014, 4, 37244-37265.

4 M. Kidwai, A. Jain, A. Sharmab and R. C. Kuhad, Catal. Sci. Technol., 2013, 3, 230-234.

5 X. X. Gao, S. S. Huang, P. P. Dong, C. Wang, J. Hou, X. K. Huo, B. J. Zhang, T. H. Ma and X. C. Ma, Catal. Sci. Technol., 2016, 6, 3585-3593.

6 L. Heap, A. Green, D. Brown, B. V. Dongen and N. Turner, Catal. Sci. Technol., 2014, 4, 2251-2259.

7 N. L. McCombs, T. Smirnova and R. A. Ghiladi, Catal. Sci. Technol., 2017, 7, 3104-3118.

8 N. C. Veitch, Phytochemicals, 2004, 65, 249-259.

9 N. Hakulinen and J. Rouvinen, Cell. Mol. Life Sci., 2015, 72, 857-868.
10 Z. C. Liu, T. Xie, Q. P. Zhong and G. G. Wang, Acta Crystallogr., Sect. F: Struct. Biol. Commun., 2016, 72, 328-335.

11 N. E. Es-Safi, S. Ghidouche and P. H. Ducrot, Molecules, 2007, 12, 2228-2258.

12 S. Ghidouche, N. E. Es-Safi and P. H. Ducrot, Tetrahedron Lett., 2008, 49, 619-623.

13 H. M. Awad, M. G. Boersma, J. Vervoort and I. M. C. M. Rietjens, Arch. Biochem. Biophys., 2000, 378, 224-233.

14 L. G. Fenoll, P. A. García-Ruiz, R. Varón and F. GarcíaCánovas, J. Agric. Food Chem., 2003, 51, 7781-7787.

15 N. C. Veitch and R. J. Grayer, Nat. Prod. Rep., 2008, 25, 555611.

16 V. Krishnamachari, L. H. Levine and P. W. Paré, J. Agric. Food Chem., 2002, 50, 4357-4363.

17 K. Mohammad, I. Mohammad, R. Wasiur, H. Noriko, O. Masayoshi and K. Nobusuke, J. Chem. Soc., Perkin Trans. 1, 1981, 553-559.

18 G. Sagrera and G. Seoane, Synthesis, 2010, 2776-2786.

19 I. Ahmed, K. Ishratullah, M. Ilyas, W. Rahman, O. Seligmann and H. Wagner, Phytochemistry, 1981, 20, 1169-1170.

20 C. Ichino, H. Kiyohara, N. Soonthornchareonnon, W. Chuakul, A. Ishiyama, H. Sekiguchi, M. Namatame, K. Otoguro, S. Omura and H. Yamada, Planta Med., 2006, 72, 611-614.

21 L. V. Jqrgensen, C. Cornett, U. Justesen, L. H. Skibsted and L. O. Dragsted, Free Radical Res., 1998, 29, 339-350.

22 M. H. Vakarelska-Popovska and Z. Velkov, Comput. Theor. Chem., 2016, 1077, 87-91.

23 G. I. Berglund, G. H. Carlsson, A. T. Smith, H. Szöke, A. Henriksen and J. Hajdu, Nature, 2002, 417, 463-468.

24 T. Bertrand, C. Jolivalt, P. Briozzo, E. Caminade, N. Joly, C. Madzak and C. Mougin, Biochemistry, 2002, 41, 73257333.

25 A. D. Mackerell, M. Feig and C. L. Brooks, J. Comput. Chem., 2004, 25, 1400-1415.

26 A. W. Schüttelkopf and D. M. F. van Aalten, Acta Crystallogr., Sect. D: Biol. Crystallogr., 2004, 60, 1355-1363.

27 G. M. Morris, R. Huey, W. Lindstrom, M. F. Sanner, R. K. Belew, D. S. Goodsell and A. J. Olson, J. Comput. Chem., 2009, 30, 2785-2791. 